\title{
A Study on Exhaust Muffler Counteract
}

\author{
Ying-li Shao \\ Department of Statistics and Mathematics Inner Mongolia Finance and Economics College \\ Huhhot, P. R. China \\ yinglishao@163.com
}

\begin{abstract}
Keywords: Counter-phase, Diesel engine, Muffle, Insertion loss
Abstract. The exhaust noise, which falls into low-frequency noise, is the dominant noise source of a diesel engines and tractors. The traditional exhaust silencers, which are normally constructed by combination of expansion chamber, and perforated pipe or perforated board, are with high exhaust resistance, but poor noise reduction especially for the low-frequency band noise. For this reason, a new theory of exhaust muffler of diesel engine based on counter-phase counteracts has been proposed. The mathematical model and the corresponding experimental validation for the new exhaust muffler based on this theory were performed.
\end{abstract}

\section{Introduction}

Exhaust noise, a kind of bump, is the main noise source of diesel engines and tractors. Installing exhaust muffler is the most direct and effective method to control the exhaust noise [1]. But most of the traditional exhaust mufflers are composed of expansion chamber, and perforated pipe or perforated board [2], whose exhaust resistance is rather great and whose function of noise reduction is very poor, especially for the low frequency, which is the major part of exhaust noise [3]. Pointing at the problem in the traditional mufflers of diesel engines, the author puts forth a new theory of exhaust silencer of diesel engine based on counter-phase counteract and split-gas rushing. The dominant low-frequency noise components are controlled by counteract of two sound waves with counter-phases $\left(180^{\circ}\right.$ phase difference), the other frequency-band noise is reduced by lowering the exhaust gas flow rate thus lowering exhaust noise. In addition, the author establishes a physics model of counter-phase counteract, founds a mathematics modelling on the basis of and analyses the acoustical characteristics of the abovementioned physics model, deduces theoretical model of the transmission loss of the new muffler, and founds the relationship between its acoustic characteristics and the major parameters of framework. Thereafter, according to the new theory, taking the single-cylinder diesel engine of CG25 as the sample model machine, the author designs an exhaust muffler, and tests and verifies the new theory and the theoretical analysis.

\section{Principle of the muffler}

The principle of the new muffler is shown in Fig.1. The muffler unit is mainly composed of an outer tube and an inside tube. There are two round and opposite holes in the inside tube, and the sizes of the two holes are same, and the summation of the sectional areas of the two holes is no less than the sectional area of the entrance of the inside tube. With the help of the U-tube, the exhaust noise enters from the entrance, and counter-phase when it enters the inside tube of the muffler, along the upper passages and lower passages. In accordance with the theory of sound radiation, the author can regard the two opposite holes as the two plunger sound source, and due to the reverse oscillation, the radiation capability of the combined sound resource is reduced, so the author can reach the aim of noise reduction. 


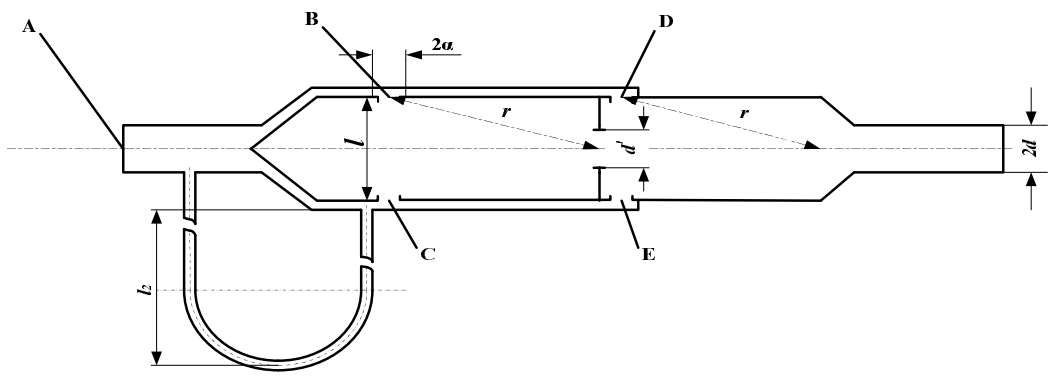

Fig. 1Principle of the muffler using reversed-phase cancelling

\section{Analysis of the experimental results}

The theoretical formula for transmission loss of the new type muffler

$$
\mathrm{TL}=20 \log \frac{2 r^{2}}{a k d l}
$$

The author designs 3 series of data and name them as Muffler TypeI, Muffler TypeII and Muffler TypeIII, and their sizes are as the following:

Muffler TypeI: $\mathrm{r}=165 \mathrm{~mm}, \mathrm{l}=80 \mathrm{~mm}$;

Muffler TypeII: $r=165 \mathrm{~mm}, 1=60 \mathrm{~mm}$;

Muffler TypeIII: $\mathrm{r}=56 \mathrm{~mm}, 1=80 \mathrm{~mm}$

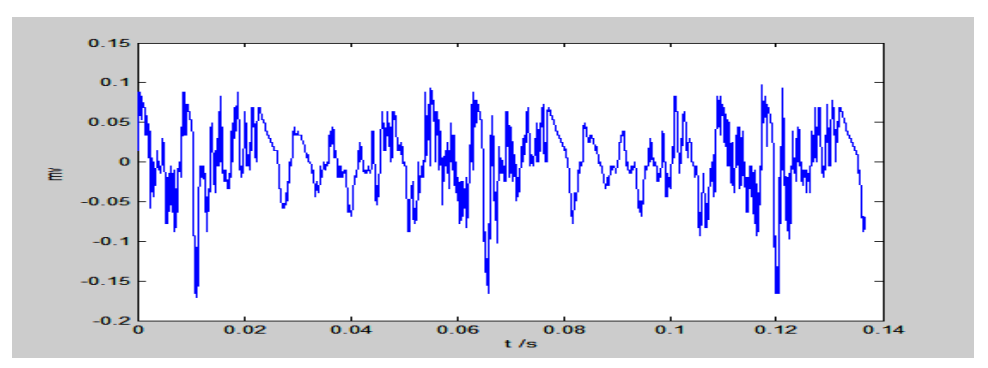

Fig. 2The time domain signal of the new I at 2000r/min

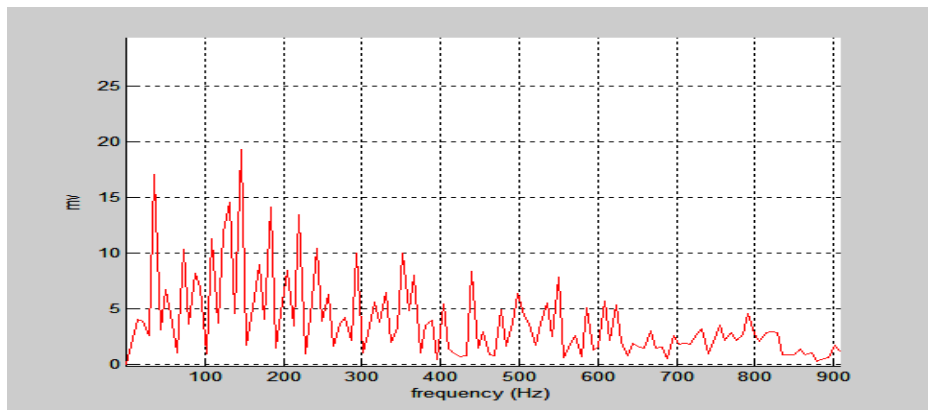

Fig. 3The spectrum of the new I muffler at 2200r/min 


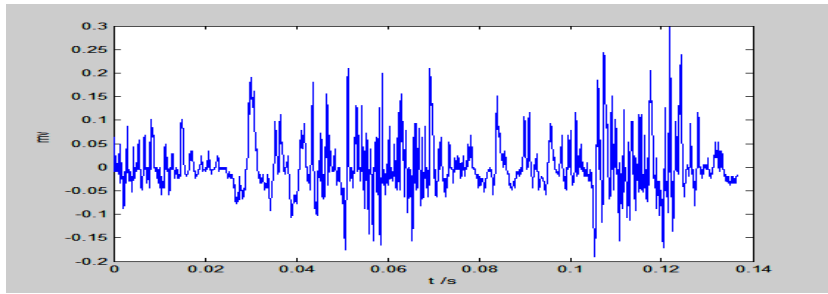

Fig. 4The time domain signal of the newIIIat 2000r/min

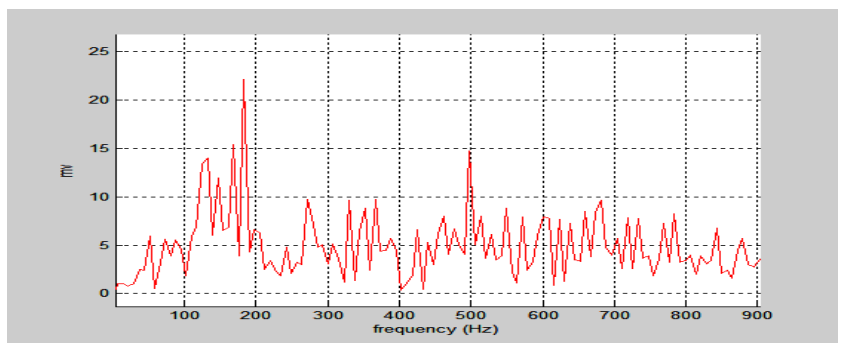

Fig. 5The spectrum of the newIII muffler at 2200r/min

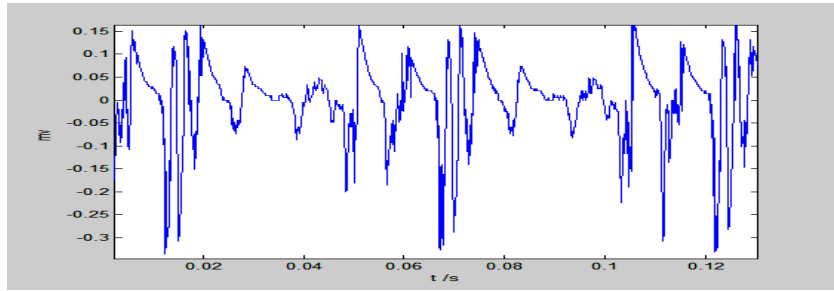

Fig. 6The time domain signal of the original muffler at 2000r/min

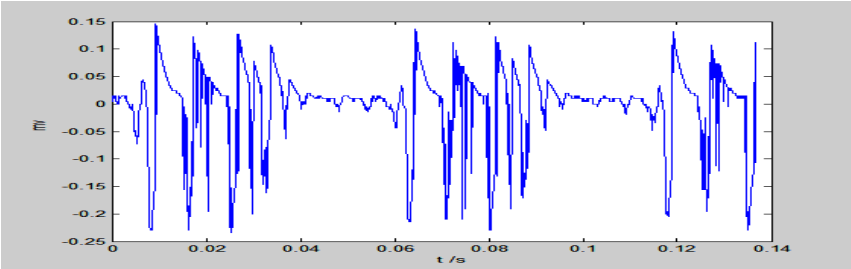

Fig. 7The time domain signal of the blank pipe at 2000r/min

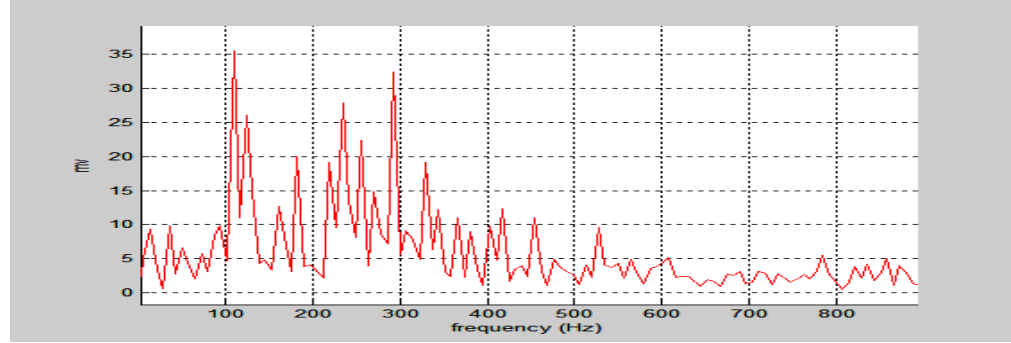

Fig. 8The spectrum of the blank pipe at $2200 \mathrm{r} / \mathrm{min}$

The tested results show that the insertion loss of three new mufflers has all reached $7 \mathrm{~dB}(\mathrm{~A})$, more than $4 \mathrm{~dB}(\mathrm{~A})$ improved compared to original muffler. The original muffler can only reduce the highfrequency noise components, it cannot reduce, even strengthen the noise of frequency below $500 \mathrm{~Hz}$, proved conventional muffler with poor capacity of lowering the low-frequency noise again. The new exhaust mufflers were obviously effective in controlling the low-frequency exhaust noise, which proved correctness of the new theory. In addition, it has been found that the new mufflers have a good effect of 
noise control in the whole frequency domain especially in the range of under $500 \mathrm{~Hz}$. This not only proved that the new mufflers have very good performance for low-frequency noise reduction, but also proved that using split-gas rushing can lower the air flow speed thus lowering the air-regeneration noise. The counter-phase is only effective to the exhaust noise of the target frequency and its odd multiple harmonics instead of the whole frequency range, but the split-gas rushing is working to the noise in all frequency range. By comparing the results of three new mufflers, it was noticed that the new muffler type II was the best, especially at the rated speed the effect is more pronounced, which is consistent with the theoretical model analysis, further proved the correctness of the theory.

\section{Summary}

Taking the single-cylinder diesel engine CG25 as the experimental engine, the exhaust noise was measured and its spectrum was analyzed. In order to accurately extract the exhaust noise as the control target, the singular value decomposition technique was utilized for decomposition and reconstruction of the signal. Based on this, three new mufflers with different parameters were designed and manufactured. The sound level pressure $\mathrm{dB}$ (A), octave-band sound pressure level as well as detailed spectrum of exhaust noise from the tested diesel engine with three new mufflers were measured and analyzed respectively at five different speeds. By comparing the results with that without muffler and with the original muffler of the engine, the new theory of muffler has been verified.

\section{References}

[1] A.D.Sahasrabudhe,S.Anantha Ramu , M.L.Munjal.Matrix condensation and transfer matrix techniques in the 3-D analysis of expansion chamber mufflers[J].Journal of Sound and Vibration,1991,147(3),pp.371-394.

[2] Mara Cuesta,Pedro Cobo:Active Control of the Exhaust Noise Radiated by an Enclosed Generator [J]. Applied Acoustics,2000(61),pp.83-94.

[3] T.Kar , M.L.Munjal.Generalized analysis of a muffler with any number of interacting ducts[J].JournalofSoundandVibration,2005,285(3),pp.585-596.

[4] T.W.Wu,P.Zang , C.Y.R.Cheng.Boundary element analysis of mufflers with an improved method for deriving the four-pole parameters[J].Journal of Sound and Vibration,1998,217(4),pp.767-779.

[5] Bilawchuk,K.R.Fyfe:Comparison and implementation of the various numerical methods used for calculating transmission loss in silencer systems.Applied Acoustic,2003,64(9),pp.903-91.

[6] Huang Lixi.A:theoretical study of duct noise control by flexible pane[J]. JASA,1999,106(4),pp.1801-1809.

[7] F.D.Denia,J.Albelda,F.J.Fuenmayor,A.J.Torregrosa.Acoustic behaviour ofellipticalmufflers[J].JournalofSoundandVibration,2001,241(3),pp.401-421. 